\title{
An evolved xylose transporter from Zymomonas mobilis enhances sugar transport in Escherichia coli Chuan Ren ${ }^{1}$, Tingjian Chen ${ }^{1}$, Jingqing Zhang1,2, Ling Liang1 and Zhanglin Lin*1
}

\author{
Address: ${ }^{1}$ Department of Chemical Engineering, Tsinghua University, One Tsinghua Garden Road, Beijing 100084, PR China and ${ }^{2}$ Department of \\ Chemical Engineering, Massachusetts Institute of Technology, Cambridge, MA 02139, USA \\ Email: Chuan Ren - rc@mails.tsinghua.edu.cn; Tingjian Chen - chentj02@mails.tsinghua.edu.cn; Jingqing Zhang - jingqing@mit.edu; \\ Ling Liang - liangling99@gmail.com; Zhanglin Lin* - zhanglinlin@mail.tsinghua.edu.cn \\ * Corresponding author
}

Published: I5 December 2009

Microbial Cell Factories 2009, 8:66
Received: 18 October 2009

Accepted: 15 December 2009

his article is available from: http://www.microbialcellfactories.com/content/8///66

(c) 2009 Ren et al; licensee BioMed Central Ltd.

This is an Open Access article distributed under the terms of the Creative Commons Attribution License (http://creativecommons.org/licenses/by/2.0), which permits unrestricted use, distribution, and reproduction in any medium, provided the original work is properly cited.

\begin{abstract}
Background: Xylose is a second most abundant sugar component of lignocellulose besides glucose. Efficient fermentation of xylose is important for the economics of biomass-based biorefineries. However, sugar mixtures are sequentially consumed in xylose co-fermentation with glucose due to carbon catabolite repression (CCR) in microorganisms. As xylose transmembrance transport is one of the steps repressed by CCR, it is therefore of interest to develop a transporter that is less sensitive to the glucose inhibition or CCR.
\end{abstract}

Results: The glucose facilitator protein Glf transporter from Zymomonas mobilis, also an efficient transporter for xylose, was chosen as the target transporter for engineering to eliminate glucose inhibition on xylose uptake. The evolution of Glf transporter was carried out with a mixture of glucose and xylose in E. coli. Error-prone PCR and random deletion were employed respectively in two rounds of evolution. Aided by a high-throughput screening assay using xylose analog $p-$ nitrophenyl- $\beta$-D-xylopyranoside ( $\mathrm{PNPX}$ ) in 96-well plates, a best mutant 2-RD5 was obtained that contains several mutations, and a deletion of 134 residues (about $28 \%$ of total residues), or three fewer transmembrane sections (TMSs). It showed a 10.8-fold improvement in terms of pNPX transport activity in the presence of glucose. The fermentation performance results showed that this mutant improved xylose consumption by $42 \%$ with $M 9$ minimal medium containing $20 \mathrm{~g} \mathrm{~L}^{-1}$ xylose only, while with the mixture sugar of xylose and glucose, $28 \%$ more glucose was consumed, but no obvious co-utilization of xylose was observed. Further glucose fed-batch experiments suggested that the intracellular metabolism of xylose was repressed by glucose.

Conclusions: Through random mutagenesis and partial deletion coupled with high-throughput screening, a mutant of the Glf transporter (2-RD5) was obtained that relieved the inhibition of xylose transport by glucose. The fermentation tests revealed that 2-RD5 was advantageous in xylose and glucose uptakes, while no obvious advantage was seen for xylose co-consumption when co-fermented with glucose. Further efforts could focus on reducing CCR-mediated repression of intracellular metabolism of xylose. Glf should also serve as a useful model to further exploit the molecular mechanism of xylose transport and the CCR-mediated inhibition. 


\section{Background}

Currently, most of the industrial materials and fuels are made from petroleum, which is irreversibly being depleted. Lignocellulosic biomass, the most abundant raw material from hardwood, softwood, agricultural residues and grasses, is seen as an enormous potential feedstock for future production of valuable chemicals and biofuels [1-3]. In biorefinery, several bacteria, yeasts, and fungi have been used for processing lignocellulosic biomass into various industrial chemicals such as ethanol, succinic acid, lactic acid, butanol and acetone [4-6]. DXylose is a second most abundant sugar component of lignocellulose besides glucose, and comprises up to $25 \%$ of the total sugar content in lignocellulosic hydrolysates [7-9]. However, sugar mixtures are sequentially consumed in fermentation due to carbon catabolite repression (CCR) in microorganisms [10], which significantly reduce productivity and efficiency of the biorefinery processes. Therefore, the efficient co-utilization of xylose with glucose is a prerequisite for large-scale production of biofuels and biochemicals.

In Escherichia coli, regulation of CCR is brought about by the modulation of the phosphorylation state of EIIAGlc, which is encoded by the $c c r$ gene and an IIA component of the glucose-specific phosphoenolpyruvate-carbohydrate phosphotransferase system (PTS). In the presence of glucose, EIIAGlc is preferentially dephosphorylated and binds to non-PTS permeases and also down-regulate genes related to metabolism of non-PTS sugars, including xylose $[10,11]$. Previously, components of the PTS or related systems have been knocked out to reduce glucose inhibition [12-16], but with mixed outcomes [13]. We sought a different approach by firstly modifying xylose transporters to reduce glucose inhibition on xylose uptake.

Glucose facilitator protein Glf transporter (encoded by the glf gene) from Zymomonas mobilis belongs to the major facilitator superfamily (MFS) class of proteins [17]. It is a low-affinity, high-velocity carrier which also transports fructose, xylose in addition to glucose. This type of facilitators functions without additional energy but only relies on the cross-membrane concentration gradients of sugars, and thus is energetically more efficient. Glf transporter also can take up xylose rapidly with a maximum rate twice that for glucose at $5^{\circ} \mathrm{C}[18]$, although glucose is still utilized preferentially when co-fermenting with xylose for a recombinant xylose-fermenting strain of $Z$. mobilis CP4(pZB5) [19]. Furthermore, this protein has been functionally expressed in $E$. coli strains for transporting glucose and fructose [20]. And in our previous work, it has been shown that the xylose transport activity of Glf transporter was totally inhibited in the presence of glucose in E. coli [21]. Taken together, Glf transporter is a useful transporter for studying the glucose inhibition and for creating improved xylose carrier variants with enhanced activity in the presence of glucose.

Although there is no report about the structure of the Glf transporter, lactose permease (LacY) from E. coli, which belongs to the same MFS class of proteins, has been studied in detail. LacY is a cytoplasmic membrane protein with 12 hydrophobic transmembrane $\alpha$-helical domains with the $\mathrm{N}$ - and $\mathrm{C}$ - termini on the cytoplasmic face of the membrane. A study on LacY revealed that several residues in its cytoplasmic loops IV/V and VI/VII played an important role in the binding of unphosphorylated EIIA Glc [16]. This provides important clues for engineering of Glf transporter.

In this study, we proposed to eliminate the interaction between Glf transporter and EIIAGlc in E. coli by manipulating Glf transporter directly. Error-prone PCR [22,23] and random deletion [24-26] strategies were employed in two rounds of directed evolution respectively to create Glf transporter libraries. Existing analyses of xylose uptake were commonly involved in utilizing isotopic substrates or high-performance liquid chromatography (HPLC) $[20,27,28]$, which were not the appropriate methods for screening due to complicated operations. We recently developed a high-throughput screening method for xylose transporter assay in vivo by co-expressing xylosidase from Bacillus pumilus (XynB) with Glf transporter, which was able to utilize a commercially available xylose analog, $p$ nitrophenyl- $\beta$-D-xylopyranoside (pNPX) [21]. From the Glf transporter mutant libraries screened with this XynBmediated assay in 96-well plates, a successful mutant was obtained which was 10.8 -fold more efficient than the wild type in transporting xylose in LB medium supplemented with $20 \mathrm{~g} \mathrm{~L}^{-1}$ glucose while the xylose transport activity of the wild type was totally inhibited by glucose. The fermentation performance of this mutant in the presence of xylose and/or glucose was also evaluated and discussed.

\section{Results and Discussion \\ First round evolution of Glf transporter}

In the first round of directed evolution, error-prone PCR was used to engineer Glf transporter. The template pET30a-glf-xynB was constructed as previously reported, and $0.15 \mathrm{mM} \mathrm{Mn}^{2+}$ was added following the standard error-prone PCR protocol. The library was transformed into E. coli BL21(DE3). 3000 variants were screened using the XynB-mediated high-throughput screening method in 96-well plate [21], and a best mutant 1-6C7 was obtained. It showed about one-fold improvement in transporting pNPX compared with the wild type in LB medium supplemented with $20 \mathrm{~g} \mathrm{~L}^{-1}$ glucose, while there was no statistically significant difference between its transport activity and that of wild type in the absence of glucose $(p=0.509)$ 
(Table 1). Sequencing showed that it contained six amino acid mutations compared with wild type Glf (H215Q, T242W, D251V, Q279R, N427H and G469W).

\section{Second round evolution of Glf and secondary structure prediction by HMMTOP}

While the improvement in the first round of evolution was significant ( $\mathrm{p}=0.035)$, it was insufficient for our purpose. We thus took a more focused approach by carefully examining the Glf loops. The study on E. coli lactose permease (LacY), a close relative of Glf, suggested several possible residues in its cytoplasmic loops targeted by the unphosphorylated EIIAGlc [16], an essential step for the CCR effect. This prompted us to carefully examine the Glf loops. As the structure of Glf transporter was unknown, we predicted its secondary structures by HMMTOP [2931]. As shown in Figure 1A, the model suggested that Glf had 12 transmembrane sections (TMSs) and both $\mathrm{N}$ - and $\mathrm{C}$ - termini were in the cytoplasm. Corresponding amino acid residues for the 12 TMSs were 13-35, 52-73, 86-105, 124-146, 159-176, 197-218, 258-277, 304-322, 335-354, 367-386, 399-417 and 434-451. The large loop between helices VI and VII were subsequently chosen for random deletion. To this end, $S c a$ I site was introduced in the loop using pET30a-glf(1-6C7)-xynB as template. The protocol was designed as such that the two Glf DNA fragments progressively deleted from the point of Sca I were then mixed randomly again in re-ligation, by extracting the second set of DNA fragments from the linearized plasmid (Figure 2D) and then ligated back into the same plasmid (Figure $2 \mathrm{E})$. This created a library of Glf variants that were truncated randomly at either end of the reference point of the Sca I site. A total of 2350 variants were screened by the XynB method with $20 \mathrm{~g} \mathrm{~L}^{-1}$ glucose in the medium in 96 well plates, and good mutants were confirmed by growing the cells in test tubes. A best mutant, 2-RD5, was obtained, which showed a 10.8 -fold improvement $(\mathrm{p}=0.009)$ in terms of pNPX transport activity in the presence of glucose. In the LB medium alone, the pNPX transport activity of 2-RD5 was also slightly higher than that of the wild type (Table 1), although this increase was not statistically significant $(\mathrm{p}=0.406)$. Sequencing revealed it had about a deletion of 134 residues (about $28 \%$ of the total residues) and contained one additional amino acid mutation
(R336S) compared with the template 1-6C7. According to the model predicted by HMMTOP (Figure 1B), TMSs V, VI and VII were completely deleted together with parts of the loops between IV/V and VII/VIII in mutant 2-RD5, and the $\mathrm{N}$-terminus was now on the outside of the cytoplasm, while the C-terminus was on inside of the cytoplasm. It should also be noted that only two of the original mutations in the template 1-6C7 remained in 2-RD5. The functions of these three point mutations (including the additional mutation generated during random deletion) require further dissection.

\section{Characterization of xylose transport activity of 2-RD5 in the presence of glucose}

In the previous work [21], we showed that xylose and its analog pNPX were competing substrates in terms of Glf transport, and thus the two transport activities were correlated. To quantitatively correlate the transport behaviours of xylose and its analog pNPX for the best mutant 2-RD5, similarly inhibition experiments were again carried out, but in the presence of glucose. The whole cell pNPX transport activity was measured in the presence of different concentrations of xylose. As shown in Figure 3B, for mutant 2-RD5 in the presence of glucose, the inhibition by xylose still matched the classical Michaelis-Menten equation (the $\mathrm{R}^{2}$ value was 0.990 ). In contrast, for the wild type in the presence of glucose, the transport activity of pNPX was approximately constant in different concentration of xylose, and close to the background (about $2 \mathrm{nmol}$ $\mathrm{min}^{-1} \mathrm{mg} \mathrm{dw} \mathrm{dw}^{-1}$ ) (Figure 3A), indicating an almost total inhibition by glucose. These results showed that the mutant 2-RD5 significantly improved xylose transport activity in the presence of glucose.

\section{Fermentation performance of 2-RD5}

Consumption of xylose in the presence or absence of glucose for E. coli BL21(DE3) cells harbouring pET30a-glf(2RD5) - $x y n B$ were evaluated at $37^{\circ} \mathrm{C}$, and normalized by cell dry weight. BL21(DE3)/pET30a and BL21(DE3)/ pET30a-glf-xynB were monitored simultaneously as controls. Typical fermentation results are shown in Figures 4 and 5. After cultivated in M9 minimal medium supplemented with $20 \mathrm{~g} \mathrm{~L}^{-1}$ xylose for over 82 hours, $9.1 \mathrm{~g} \mathrm{~L}^{-1}$ xylose was consumed, about $42 \%$ more than the control

Table I: whole cell pNPX transport assay results for wild type Glf and its mutants.

\begin{tabular}{|c|c|c|c|c|}
\hline \multirow[t]{2}{*}{ BL2 I (DE3)/pET30a-glf-xynB } & \multicolumn{2}{|c|}{$\begin{array}{l}\text { Whole cells assay } \\
\left(\mathrm{nmol} \mathrm{min}^{-1} \mathrm{mg} \mathrm{dw}^{-1}\right)\end{array}$} & \multicolumn{2}{|c|}{ p value } \\
\hline & LB & LB/GIC & LB & LB/GIc \\
\hline wild type & $14.6 \pm 2.0$ & $0.6 \pm 0.2$ & - & - \\
\hline $1-6 C 7$ & $12.9 \pm 0.3$ & $1.2 \pm 0.1$ & 0.509 & 0.035 \\
\hline 2-RD5 & $17.8 \pm 2.6$ & $7.1 \pm 0.8$ & 0.406 & 0.009 \\
\hline
\end{tabular}

LB/Glc, LB medium supplemented with $20 \mathrm{~g} \mathrm{~L}^{-1}$ glucose; the standard deviations shown above were from triplicate independent cultures. 

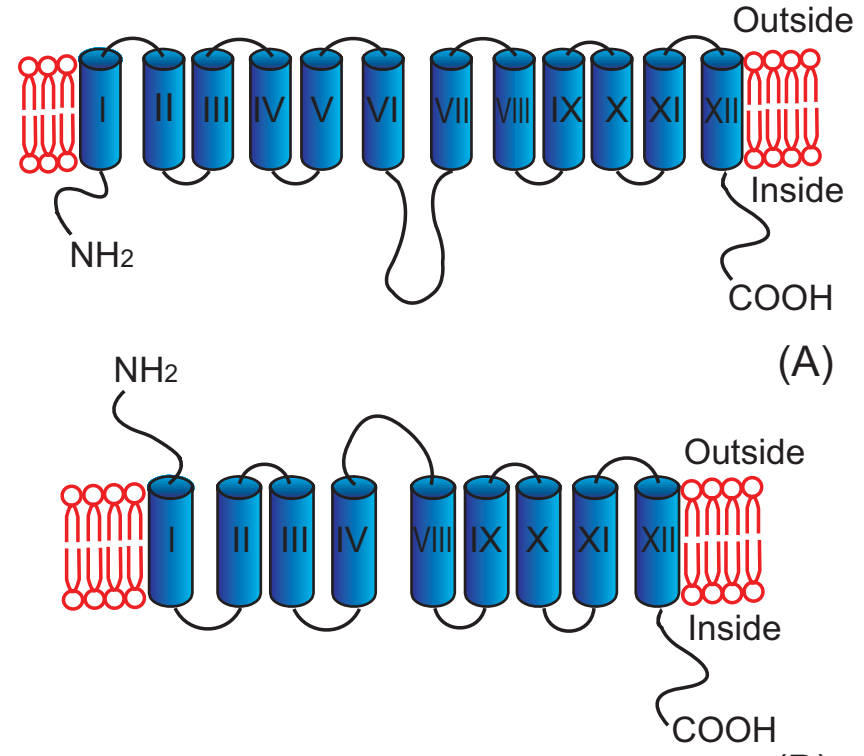

(B)

Figure I

Secondary structure models of the wild type GIf and the mutant 2-RD5 predicated by HMMTOP. (A) Wild type Glf has 12 TMSs and both $\mathrm{N}$ - and $\mathrm{C}$ - termini are inside the cytoplasm. (B) Mutant 2-RD5 has 9 TMSs and N-terminus is on the outside of the cytoplasm, while $\mathrm{C}$-terminus is on the inside of the cytoplasm.

BL21(DE3)/pET30a-glf-xynB (Figure 5A), which was significantly higher than the standard deviation of $1.5 \%$ observed for xylose consumption in this study. Consistently, BL21(DE3)/pET30a-glf(2-RD5)-xynB produced $41 \%$ more biomass (Figure $4 \mathrm{~A}$ ). On the other hand, when minimal medium supplemented with $10 \mathrm{~g} \mathrm{~L}^{-1}$ glucose and $10 \mathrm{~g} \mathrm{~L}^{-1}$ xylose was used, BL21(DE3)/pET30a-glf(2-RD5)$x y n B$ consumed $8.5 \mathrm{~g} \mathrm{~L}^{-1}$ glucose at 82 hours, about $27 \%$ more than the control BL21(DE3)/pET30a-glf-xynB (Figure $5 \mathrm{~B}$ ), and $30 \%$ more biomass was produced (Figure $4 \mathrm{~B})$. These results showed that the Glf transporter mutant 2-RD5 enhanced its sugar transport property, both for xylose (in the presence of xylose alone) and glucose. However, in the minimal medium supplemented with $10 \mathrm{~g} \mathrm{~L}^{-1}$ xylose and $10 \mathrm{~g} \mathrm{~L}^{-1}$ glucose, there was no obvious consumption of xylose for all of the strains, including BL21(DE3)/pET30a-glf(2-RD5)-xynB. This was in direct contradiction to the greatly improved xylose transport in the presence of glucose, demonstrated by the PNPX assay. A plausible explanation might be that while the inhibition of xylose transport by glucose was relieved, the inhibition of intracellular xylose metabolism mediated by glucose now became the rate-limiting step.

A set of glucose-fed batch cultivation experiments was done to verify the metabolism inhibition of xylose. The
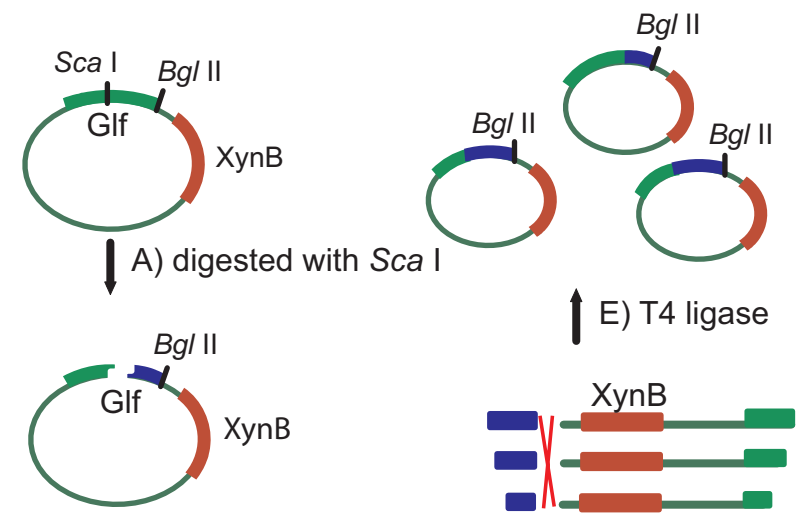

B) Exonuclease III
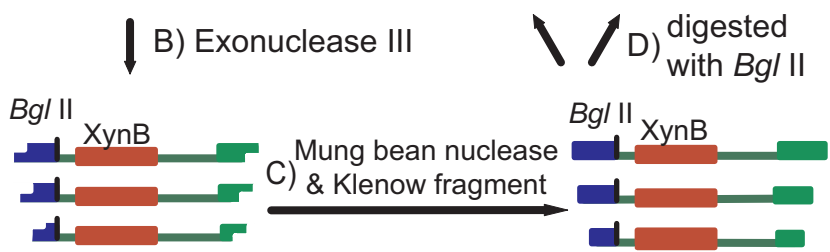

Figure 2

Schematic overview of random deletion used in this study. A) Linearization of the plasmid by restriction digestion at Sca I site. B) Random deletion with Exo III. C) Bluntended with mung bean nuclease and Klenow fragment. D) Single digested with $\mathrm{Bg} / \mathrm{II}$. E) Random ligation with T4 DNA ligase.

three strains were first inoculated in the minimal medium with $20 \mathrm{~g} \mathrm{~L}^{-1}$ xylose alone, IPTG was added to induce the expression of the transporter when the OD reached 0.6, and then $5 \mathrm{~g} \mathrm{~L}^{-1}$ glucose was added after 1 hour induction. As shown in Figure 5C, when glucose was supplemented, xylose utilization was gradually inhibited in all three strains. After 8 10 hours, the xylose consumption was essentially ceased. These results suggested that glucose supplementation affected the downstream xylose metabolism and gradually blocked the xylose utilization, Consistent with the co-fermentation results (Figure 5B), BL21(DE3)/pET30a-glf(2-RD5)-xynB almost exhausted glucose in the medium, about $28 \%$ more than BL21(DE3)/pET30a-glf-xynB (Figure 5C), and produced $34 \%$ more biomass (Figure 4C).

The fermentation results showed that, regardless what carbon sources were used, BL21(DE3)/pET30a-glf(2-RD5)$x y n B$ consumed more sugars and produced more biomass. However, in all cases it showed a significant lag phase (Figure 4A-C), for which the reason is unclear. It might be that the cells need longer time to adapt to this mutant transporter during growth. It was also interesting to note that E. coli BL21(DE3)/pET30a-glf(2-RD5)-xynB was lighter than other two strains in the equal $\mathrm{OD}_{600}$ (The unit cell dry weight of BL21(DE3)/pET30a, BL21(DE3)/ pET30a-glf-xynB and BL21(DE3)/pET30a-glf(2-RD5)-xynB 

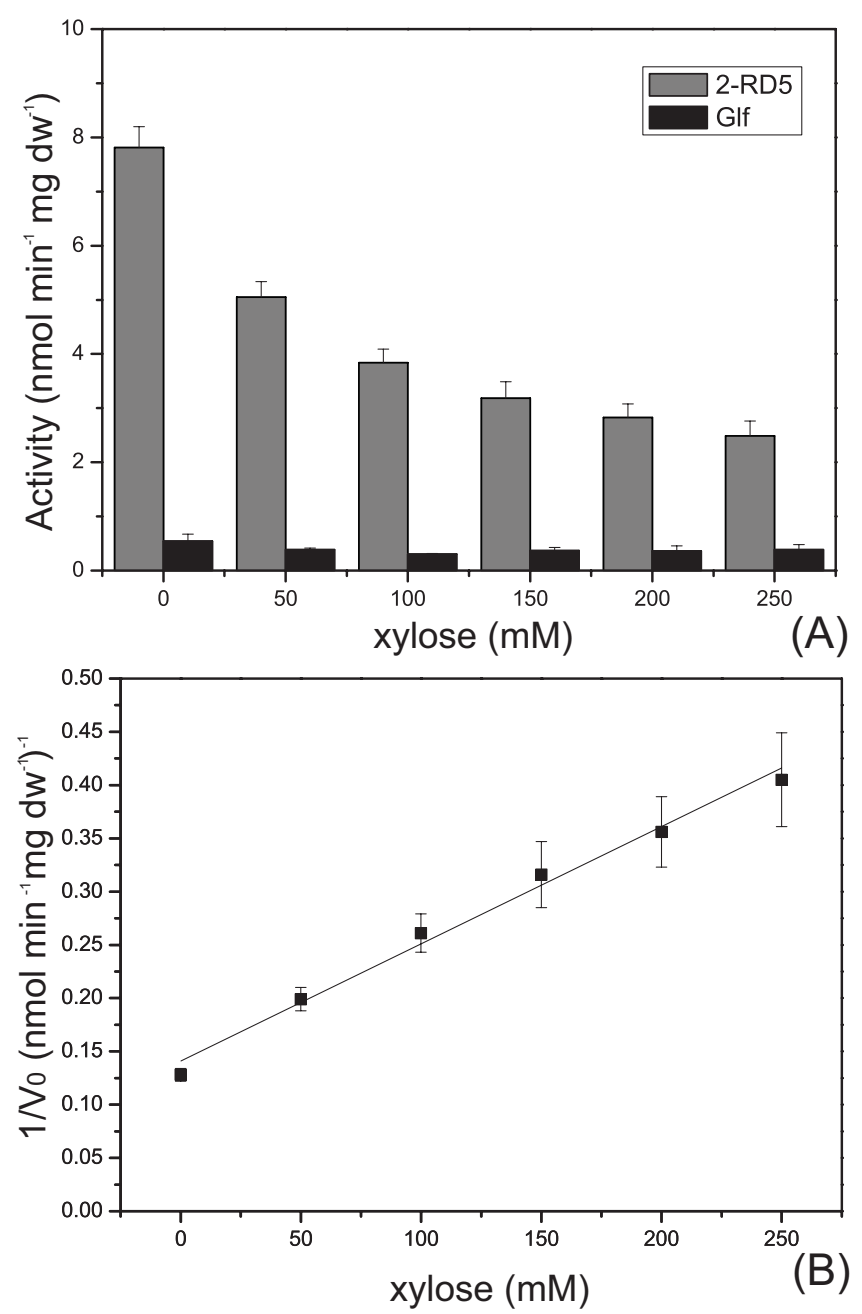

Figure 3

Xylose inhibition assay for Glf mutant 2-RD5. (A)

Xylose inhibition of pNPX transport (normalized by dry cell weight) for BL2I (DE3)/pET30a-glf(2-RD5)-xynB (gray columns) and BL2I(DE3)/pET30a-glf-xynB (black columns). The inhibition assay was done in the presence of $2 \%$ glucose. (B) Relationships between the invert of the initial velocity of PNPX transport and the concentrations of xylose for BL2 I (DE3)/pET30a-glf(2-RD5)-xynB. All data represent triplicate measurements of same cultures.

were $0.345,0.340$ and $0.247 \mathrm{mg} \mathrm{OD}^{-1}$ respectively), and the size of the cells was also slightly smaller than others judging from microscopic observations.

\section{Conclusions}

Several research groups have deleted components of PTS or related systems to reduced glucose inhibition [12-16]. As these components such as EIIAGlc take part in other cellular pathways, simple knock out may lead to unexpected effects [16]. We thus feel that engineering a transporter less sensitive to glucose represents a useful first step
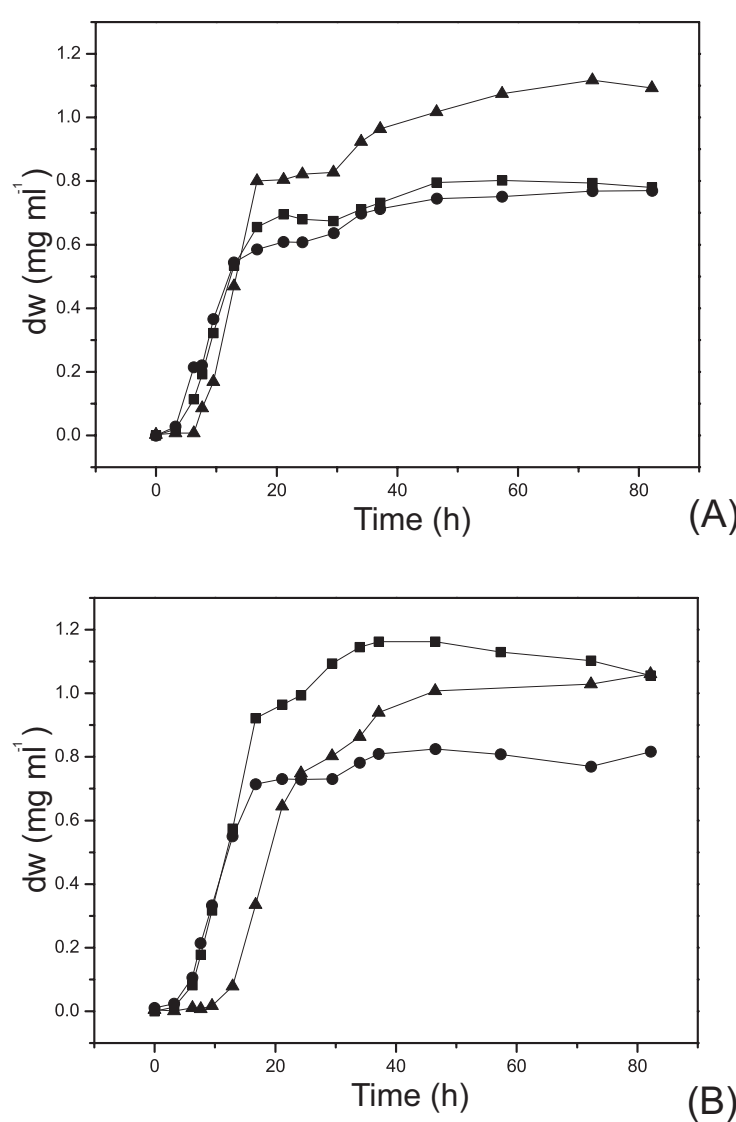

(B)

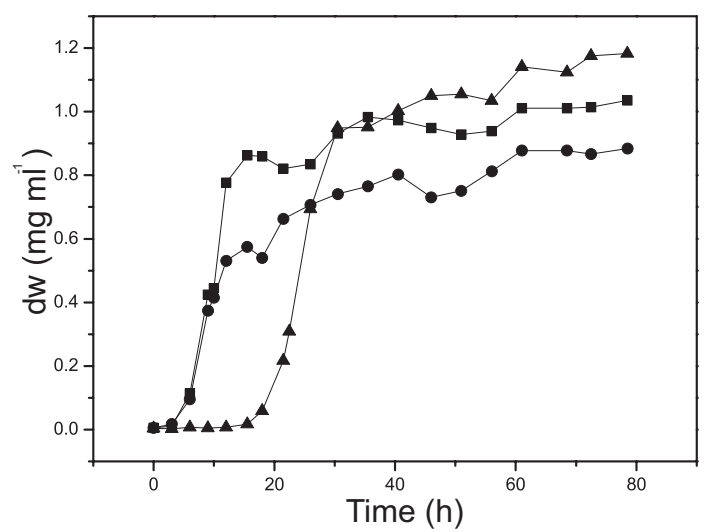

(C)

Figure 4

Growth curves of E. coli BL2 I (DE3) cells containing BL2 I (DE3)/pET30a-glf(2-RD5)-xynB, BL2 I (DE3)/ pET30a-glf-xynB and BL2 I (DE3)/pET30a. (A) in M9 minimal medium supplemented with $20 \mathrm{~g} \mathrm{~L}^{-1}$ xylose. (B) in $\mathrm{M} 9$ minimal medium supplemented with $10 \mathrm{~g} \mathrm{L-I}$ glucose and $10 \mathrm{~g}$ $\mathrm{L}^{-1}$ xylose. (C) in $\mathrm{M} 9$ minimal medium supplemented with 20 $\mathrm{g} \mathrm{L}^{-1}$ xylose, adding $5 \mathrm{~g} \mathrm{~L}^{-1}$ glucose after I h IPTG induction. $E$. coli BL2 I (DE3)/pET30a (filled black square), wild type $E$. coli BL2I (DE3)/pET30a-glf-xynB (filled black circle) and E. coli BL2 I (DE3)/pET30a-glf(2-RD5)-xynB (filled black triangle). 
toward resolving CCR. In this work, through random mutagenesis and partial deletion coupled with a high throughput screening assay, a mutant of the Glf transporter (2-RD5) was obtained that showed a much improved xylose transport activity than the wild type in the presence of glucose. The fermentation tests revealed that 2-RD5 was advantageous in xylose and glucose uptake. While no obvious advantage in xylose consumption was observed when co-fermented with glucose, this could be attributed to the inhibition on the intracellular xylose metabolism exerted by glucose, and thus further engineering to relieve this intracellular aspect of the CCR mechanism would eventually lead to efficient co-utilization of xylose with glucose in microorganisms.

Mutant 2-RD5 is much shorter than we had anticipated, a total of 134 residues were deleted, representing TMSs V, VI and VII, and parts of the loops between IV/V and VII/VIII. This presumably affects the binding of unphosphorylated EIIAGlc to Glf, as loops IV/V and VI/VII have been found to be involved in the association of EIIAGlc to a related transporter LacY [16]. Moreover, according to the prediction by HMMTOP, the orientation of first four TMSs in 2-RD5 is also inverted such that now the N-terminus is flipped to the outside of the cytoplasm. A literature search suggests that the majority of transporters consist of TMSs between 10 and 14 while some others have fewer TMSs, and those with fewer than 10 TMSs are probably present in the membrane as dimers [32]. As an example, the cardiac $\mathrm{Na}^{+}-$ $\mathrm{Ca}^{2+}$ exchanger (NCX1), a membrane protein that extrudes $\mathrm{Ca}^{2+}$ from cells using the energy of the $\mathrm{Na}^{+}$gradient has a similar structure as the predicted one for 2-RD5. It consists of nine TMSs with a large intracellular loop between TMSs V/VI and two re-entrant loops connecting TMSs II/III and TMSs VII/VIII, and its N-terminus is on the outside of the cytoplasm, while the C-terminus is on the inside of the cytoplasm $[33,34]$. NCX1 has been suggested to form a dimer in the membrane [35]. Whereas the actual structure and mechanism of 2-RD5 requires further study, we presume the functional structure of 2-RD5 might be similar to NCX1.

In future work, Glf should serve as a useful model to further exploit the molecular mechanism of xylose transport and CCR-mediated inhibition. Random or more focused mutagenesis, as well as structural analysis, of this transporter should continue to reveal useful clues, which will lead to construction of an efficient transporter for xylose.

\section{Methods}

\section{Materials}

Restriction enzymes, DNA-modifying enzymes, and DeepVent ${ }^{\circledast}$ polymerase were from New England Biolabs (Ipswich, MA, USA), Taq DNA polymerase from Takara (Dalian, China), and Pfu DNA polymerase from Tiangen
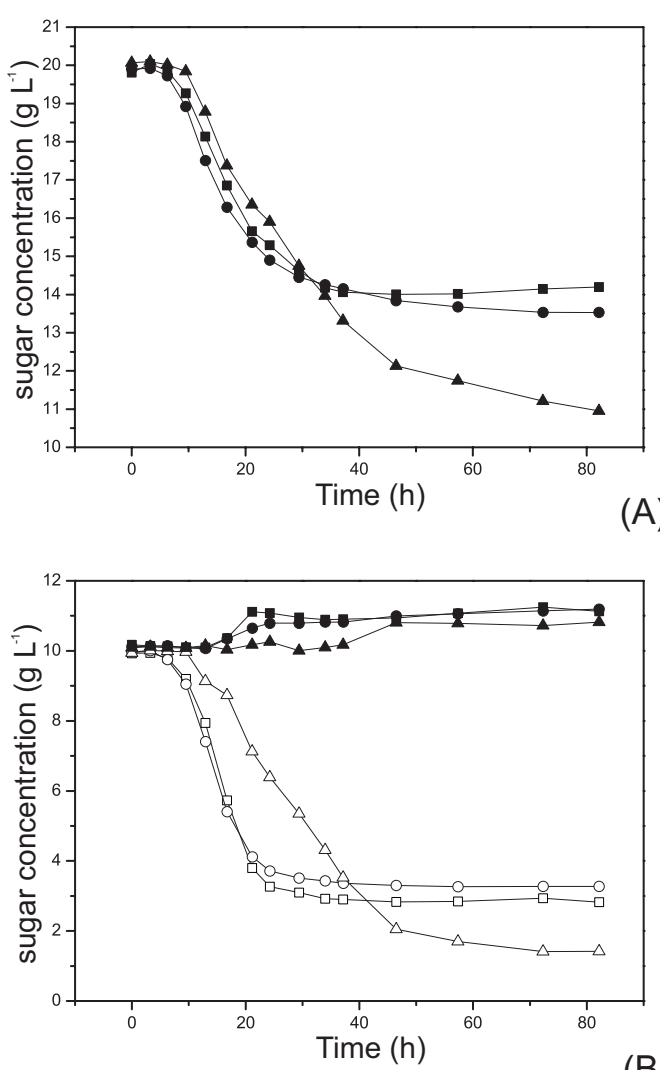

(B)

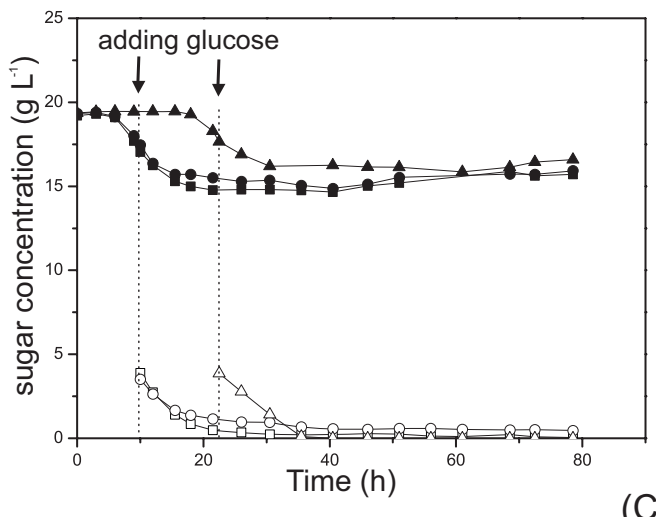

(C)

\section{Figure 5}

Sugar consumption in flask fermentation. (A) in minimal medium supplemented with $20 \mathrm{~g} \mathrm{~L}^{-1}$ xylose, B) in minimal medium supplemented with $10 \mathrm{~g} \mathrm{~L}^{-1}$ glucose and $10 \mathrm{~g} \mathrm{~L}^{-1}$

xylose, C) in $\mathrm{M} 9$ minimal medium supplemented with $20 \mathrm{~g} \mathrm{~L}^{-1}$ xylose, adding $5 \mathrm{~g} \mathrm{~L}^{-1}$ glucose after I h IPTG induction. Sugars for different strains are: xylose of $E$. coli BL2I(DE3)/pET30a (filled black square), xylose of wild type E. coli BL2I(DE3)/ PET30a-glf-xynB (filled black circle), xylose of $E$. coli BL2 I (DE3)/pET30a-glf(2-RD5)-xynB (filled black triangle), glucose of $E$. coli BL2I(DE3)/pET30a (empty square), glucose of wild type $E$. coli BL2I (DE3)/pET30a-glf-xynB (empty circle) and glucose of $E$. coli BL2I(DE3)/pET30a-glf(2-RD5)-xynB (empty triangle). 
(Beijing, China). The kits for DNA purification, gel recovery and plasmid mini-prep were either from Tiangen or QIAgen (Valencia, CA, USA). Isopropyl $\beta$-D-thiogalactoside (IPTG), and DNase I were from TaKaRa (Dalian, China). pNPX was obtained from Sigma-Aldrich (St. Louis, MO, USA). Oligonucleotides were synthesized by TaKaRa (Dalian, China) or by Sunbiotech Co., Ltd. (Beijing, China). Sequence analysis was performed either by Sangon (Shanghai, China) or by Sunbiotech. All other chemicals were of the highest grade available and were obtained from standard commercial sources. E. coli BL21(DE3) and plasmid pET30a(+) were obtained from Novagen (Wisconsin, USA). The plasmid pET30a-glf-xynB was constructed previously in this laboratory [21].

\section{Construction of random mutant library by error-prone PCR}

The glf gene was randomly mutated by a standard errorprone PCR protocol with $0.15 \mathrm{mM} \mathrm{Mn}^{2+}$ [36], The primers were as follows: forward primer epGLF, 5'-CGTATTATGGCCATTGTGACGGGTGC-3'; reverse primer GLFDOWN, 5'-AAGACCGAGATCTCTACTTCTGGGAGCGCCACAT-3' (Msc I and $B g l$ II sites are bold, respectively), and then subcloned into the Msc I - Bgl II sites in pET30a-glf-xynB. The resulting random mutant library was transformed into $E$. coli BL21(DE3) for the followingscreening.

\section{Site-directed mutagenesis}

Before the second round of evolution, Sca I site was firstly inserted into the best mutant (1-6C7) screened from the first round of directed evolution on Glf transporter in plasmid pET30a-glf(1-6C7)-xynB by site-directed mutagenesis. Overlapping PCR were carried out using the following primers, epGLF and ScaI ${ }^{1}$, 5'-TCAGATTAGG AAGTACTTGCGGTTCCAGACG-3' for reaction I; and GLFDOWN and ScaI ${ }^{2}$, 5'-GGAACCGCAAGTACTTCCTAAT CTGATGA-3' for reaction II (mutated positions are bold). The amplified DNA fragments of reaction I and II were treated with $D p n$ I respectively, and then overlapped for 10 cycles under the following conditions: $94^{\circ} \mathrm{C}$ for $1 \mathrm{~min}$, $70^{\circ} \mathrm{C}$ for $1 \mathrm{~min}$, and $72^{\circ} \mathrm{C}$ for $2 \mathrm{~min}$. The full length mutated gene was amplified with primers epGLF and GLFDOWN under 20 cycles of $94^{\circ} \mathrm{C}$ for $1 \mathrm{~min}, 63^{\circ} \mathrm{C}$ for $1 \mathrm{~min}$, and $72^{\circ} \mathrm{C}$ for $2 \mathrm{~min}$, and inserted into the Msc I - Bgl II sites in pET30a-glf-xynB to yield pET30a-glf(1-6C7)-xynBScaI.

\section{Construction of random mutant library by random deletion}

Nine micrograms of Sca I-digested pET30a-glf(1-6C7)xynB-ScaI were mixed with $15 \mu \mathrm{L}$ of $10 \times$ NEBuffer 1 (New England Biolabs) and the volume was adjusted to $150 \mu \mathrm{L}$ with deionized distilled water. The solution was equilibrated at $12{ }^{\circ} \mathrm{C}$. At time zero, 900 U Exonuclease III (Exo III) were added. $5 \mu \mathrm{L}$ samples were removed every $30 \mathrm{sec}$ thereafter for $15 \mathrm{~min}$ and added to a tube, and heated at $70^{\circ} \mathrm{C}$ for $20 \mathrm{~min}$ to fully inactivate Exo III (Figure 2B). After all the samples were collected, the single-stranded 5'overhangs were removed upon incubation with 9 U mung bean nuclease at $30^{\circ} \mathrm{C}$ for $30 \mathrm{~min}$. The reaction was quenched with $0.01 \%$ SDS, and the DNA was purified. To facilitate the re-ligation (see below), the purified DNA was blunt-ended with 3.2 U Klenow fragment in 10× NEBuffer 2 (New England Biolabs) and dNTPs (final concentration $33 \mu \mathrm{M}$ each nucleotide) for $15 \mathrm{~min}$ at $25^{\circ} \mathrm{C}$. Then EDTA was added to a final concentration of $10 \mathrm{mM}$, and the tube was incubated at $75^{\circ} \mathrm{C}$ for $20 \mathrm{~min}$ (Figure 2C). The purified DNA was then singly digested with $B g l$ II and extracted to obtain a progressively truncated library of fragments (Figure 2D). These fragments were then ligated back into the plasmid.

\section{6-well plate assay for pNPX transport activity}

E. coli BL21(DE3) cells harbouring the Glf library of the first or second round evolution were inoculated in LB medium $(200 \mu \mathrm{L})$ supplemented with kanamycin $(50 \mu \mathrm{g}$ $\mathrm{mL}^{-1}$ ) in 96-well microtiter plates. The plates were grown at $37^{\circ} \mathrm{C}$ overnight; $5 \mu \mathrm{L}$ of each culture was used to inoculate plates with $200 \mu \mathrm{L} \mathrm{LB} /$ kanamycin medium or $200 \mu \mathrm{L}$ $\mathrm{LB} /$ kanamycin medium with glucose $\left(20 \mathrm{~g} \mathrm{~L}^{-1}\right)$ in each well for expression. After $1.5 \mathrm{~h}$ of growth at $37^{\circ} \mathrm{C}$, IPTG was added to a final concentration of $1 \mathrm{mM}$, and protein expression was carried out at $37^{\circ} \mathrm{C}$ for $4 \mathrm{~h}$. For the whole cell assay, $85 \mu \mathrm{l}$ of cell culture was added into a mixture of $15 \mu \mathrm{l}$ of $6.25 \mathrm{mM}$ pNPX and $100 \mu \mathrm{l}$ of LB medium. XynB was able to cleave the xylose analog pNPX to xylose and a chromogenic group p-nitrophenol (pNP). Reactions were incubated at $37^{\circ} \mathrm{C}$ in the chamber of a SpectroMAX 190 Microtiter reader (Molecular Devices, CA), and absorbance at $405 \mathrm{~nm}$ was measured at $30 \mathrm{sec}$ intervals for 30 min. The pNPX transport activity was normalized against the respective dry cell weight. The concentration of pNP generated was calculated using a molar extinction coefficient of $18,700 \mathrm{M}^{-1} \mathrm{~cm}^{-1}$ [37]. No detectable XynB activity was found in the supernatants of the cultures of $E$. coli BL21(DE3) cells harbouring pET30a-glf-xynB, or pET30aglf(1-6C7)-xynB, or pET30a-glf(2-RD5)-xynB.

\section{Xylose competing inhibition experiment}

pNPX uptake activity of whole cell was measured in the presence of different concentration of xylose. E. coli BL21(DE3) cells harbouring plasmid pET30a-glf-xynB or pET30a-glf(2-RD5)-xynB was grown at $37^{\circ} \mathrm{C}$ in $\mathrm{LB}$ medium containing kanamycin $\left(50 \mu \mathrm{g} \mathrm{mL} \mathrm{m}^{-1}\right)$. The saturated overnight cultures were diluted 50-fold into fresh $\mathrm{LB} /$ kanamycin medium supplemented with glucose $(20 \mathrm{~g}$ $\mathrm{L}^{-1}$ ) and grown at $37^{\circ} \mathrm{C}$ for about $1.5 \mathrm{~h}$ to reach an $\mathrm{OD}_{600}$ of $0.5 \sim 0.6$. Protein expression was initiated with $1 \mathrm{mM}$ IPTG, and continued for $4 \mathrm{~h}$ at $37^{\circ} \mathrm{C}$. After that, $85 \mu \mathrm{l}$ cell culture was added into a mixture of $15 \mu \mathrm{L}$ pNPX solution 
(6.25 $\mathrm{mM})$ and $100 \mu \mathrm{L} \mathrm{LB}$ solution of xylose $(0,100 \mathrm{mM}$, $200 \mathrm{mM}, 300 \mathrm{mM}, 400 \mathrm{mM}, 500 \mathrm{mM}$ ) to initiate the whole cell reaction. The reaction and activity assay was carried out as in previous part.

\section{Flask fermentation experiments}

Single colonies of E. coli BL21(DE3)/pET30a-glf(2-RD5)$x y n B, \quad$ BL21(DE3)/pET30a-glf-xynB and BL21(DE3)/ pET30a were inoculated into $5 \mathrm{~mL} \mathrm{M9} \mathrm{minimal} \mathrm{medium}$ [38] supplemented with kanamycin $\left(50 \mu \mathrm{g} \mathrm{mL}^{-1}\right)$ and 20 $\mathrm{g} \mathrm{L}^{-1}$ xylose, or $10 \mathrm{~g} \mathrm{~L}^{-1}$ glucose and $10 \mathrm{~g} \mathrm{~L}^{-1}$ xylose, and grown at $37^{\circ} \mathrm{C}$ and $250 \mathrm{rpm}$ overnight. Then the cultures were diluted 100 -fold in to $100 \mathrm{~mL}$ medium in $500-\mathrm{mL}$ flasks, and grown at $37^{\circ} \mathrm{C}$. IPTG was added to a final concentration of $0.02 \mathrm{mM}$ when $\mathrm{OD}_{600}$ values reached $0.5 \sim 0.6$. A second set of fermentation experiments were also carried out by adding $5 \mathrm{~g} \mathrm{~L}^{-1}$ glucose into $\mathrm{M} 9$ minimal medium with $20 \mathrm{~g} \mathrm{~L}^{-1}$ xylose $1 \mathrm{~h}$ post IPTG induction to analyze the glucose effect for the fermentation of xylose. At indicated intervals, $\mathrm{OD}_{600}$ values of the cultures were recorded, and $1 \mathrm{~mL}$ culture was retrieved for determination of the xylose and glucose concentrations using highperformance liquid chromatography (Shimadzu, Kyoto, Japan), using an Aminex ion-exclusion HPX-87H cationexchange column (BioRad, California, USA) at $55^{\circ} \mathrm{C}$ with $5 \mathrm{mM} \mathrm{H}_{2} \mathrm{SO}_{4}$ as the mobile phase at a flow rate of $0.5 \mathrm{~mL}$ $\mathrm{min}^{-1}$. The sugars were detected with a RID-10A refractive index detector (Shimadzu, Kyoto, Japan). All samples for sugar analysis were filtered through $0.22 \mu \mathrm{m}$ filter membranes before using. For determination of cell dry weight, $40 \mathrm{ml}$ cells were collected at intervals after IPTG induction. The cell pellets were washed with deionized distilled water before drying. Cell dry weight was determined by drying cells in pre-weighed tubes at $65^{\circ} \mathrm{C}$ for 2 days.

\section{Lists of abbreviations}

For ease of readability, the following abbreviations were used: CCR: carbon catabolite repression; Glf: Zymomonas mobilis Glucose facilitator protein; HPLC: high-performance liquid chromatography; IPTG: Isopropyl $\beta$-D-thiogalactoside; LacY: Escherichia coli lactose permease; MFS: major facilitator superfamily; NCX1: The $\mathrm{Na}^{+} \mathrm{Ca}^{2+}$ exchanger; pNP: $p$-nitrophenol; pNPX: $p$-nitrophenyl- $\beta$-Dxylopyranoside; PTS: phosphotransferase system; TMS: transmembrane sections; XynB: Bacillus pumilus xylosidase.

\section{Competing interests}

The authors declare that they have no competing interests.

\section{Authors' contributions}

CR carried out the fermentation performance and transport activity characterization, and drafted the manuscript. TC participated in fermentation performance and transport activity characterization. JZ carried out the cloning and the first round of evolution. LL carried out the second round of evolution. ZL conceived the study, designed and supervised the experiments, and revised the manuscript. All authors read and approved the final manuscript.

\section{Acknowledgements}

This work was supported by a grant from the National Basic Research Program of China (2007CB707804). The authors thank Min Lin for Zymomonas mobilis 10232 genomic DNA.

\section{References}

I. Zaldivar J, Nielsen J, Olsson L: Fuel ethanol production from lignocellulose: a challenge for metabolic engineering and process integration. Applied Microbiology and Biotechnology 200I, 56:17-34.

2. Ohara H: Biorefinery. Applied Microbiology and Biotechnology 2003, 62:474-477.

3. Ragauskas AJ, Williams CK, Davison BH, Britovsek G, Cairney J, Eckert CA, Frederick WJ, Hallett JP, Leak DJ, Liotta CL, et al:: The path forward for biofuels and biomaterials. Science 2006, 3 I I:484-489.

4. Zverlov VV, Berezina O, Velikodvorskaya GA, Schwarz WH: Bacterial acetone and butanol production by industrial fermentation in the Soviet Union: use of hydrolyzed agricultural waste for biorefinery. Applied Microbiology and Biotechnology 2006, 7I:587-597.

5. Lin $Y$, Tanaka S: Ethanol fermentation from biomass resources: current state and prospects. Applied Microbiology and Biotechnology 2006, 69:627-642.

6. Kamm B, Kamm M: Biorefineries - Multi product processes. In White Biotechnology Volume 105. Berlin: Springer-Verlag Berlin; 2007: 175-204.

7. Lee J: Biological conversion of lignocellulosic biomass to ethanol. Journal of Biotechnology 1997, 56: I-24.

8. Saha BC: Hemicellulose bioconversion. Journal of Industrial Microbiology \& Biotechnology 2003, 30:279-29I.

9. van Maris AJA, Winkler AA, Kuyper M, de Laat WTAM, van Dijken JP, Pronk JT: Development of efficient xylose fermentation in Saccharomyces cereviside: xylose isomerase as a key component. Biofuels 2007, 108:179-204.

10. Goerke B, Stulke J: Carbon catabolite repression in bacteria: many ways to make the most out of nutrients. Nature Reviews Microbiology 2008, 6:6 I3-624.

II. Deutscher J, Francke C, Postma PW: How phosphotransferase system-related protein phosphorylation regulates carbohydrate metabolism in bacteria. Microbiology and Molecular Biology Reviews 2006, 70:939-1031.

12. Nichols NN, Dien BS, Bothast RJ: Use of catabolite repression mutants for fermentation of sugar mixtures to ethanol. Applied Microbiology and Biotechnology 200I, 56:120-125.

13. Hernandez-Montalvo V, Valle F, Bolivar F, Gosset G: Characterization of sugar mixtures utilization by an Escherichia coli mutant devoid of the phosphotransferase system. Applied Microbiology and Biotechnology 200I, 57:|86-191.

14. Flores N, Xiao J, Berry A, Bolivar F, Valle F: Pathway engineering for the production of aromatic compounds in Escherichia coli. Nature Biotechnology 1996, 14:620-623.

15. Kimata K, Takahashi H, Inada T, Postma $\mathrm{P}$, Aiba $\mathrm{H}$ : cAMP receptor protein - cAMP plays a crucial role in glucose-lactose diauxie by activating the major glucose transporter gene in Escherichia coli. Proceedings of the National Academy of Sciences of the United States of America 1997, 94:12914-12919.

16. Sondej M, Weinglass $A B$, Peterkofsky $A$, Kaback HR: Binding of enzyme IIAGIc, a component of the phosphoenolpyruvate: sugar phosphotransferase system, to the Escherichia coli lactose permease. Biochemistry 2002, 4I:5556-5565.

17. Saier $M H$, Crasnier $M$ : Inducer exclusion and the regulation of sugar transport. Research in Microbiology 1996, I 47:482-489.

18. Weisser P, Kramer R, Sprenger GA: Expression of the Escherichia coli pmi gene, encoding phosphomannose-isomerase in Zymomonas mobilis, leads to utilization of mannose as a novel growth substrate, which can be used as a selective marker. Applied and Environmental Microbiology 1996, 62:4I55-4I6I. 
19. Zhang M, Eddy C, Deanda K, Finkestein M, Picataggio S: Metabolic engineering of a pentose metabolism pathway in ethanologenic Zymomonas mobilis. Science 1995, 267:240-243.

20. Weisser P, Kramer R, Sahm H, Sprenger GA: Functional expression of the glucose transporter of Zymomonas Mobilis leads to restoration of glucose and fructose uptake in Escherichia coli mutants and provides evidence for Its facilitator action. Journal of Bacteriology 1995, 177:335I-3354.

21. Chen T, Zhang J, Liang L, Yang R, Lin Z: An in vivo, label-free quick assay for xylose transport in Escherichia coli. Analytical Biochemistry 2009, 390:63-67.

22. Cadwell RC, Joyce GF: Mutagenic PCR. PCR-Methods and Applications 1994, 3:SI36-SI40.

23. Roodveldt C, Aharoni A, Tawfik DS: Directed evolution of proteins for heterologous expression and stability. Current Opinion in Structural Biology 2005, I 5:50-56.

24. Ostermeier M, Nixon $A E$, Shim JH, Benkovic SJ: Combinatorial protein engineering by incremental truncation. Proceedings of the National Academy of Sciences of the United States of America 1999, 96:3562-3567.

25. Ostermeier M, Nixon AE, Benkovic SJ: Incremental truncation as a strategy in the engineering of novel biocatalysts. Bioorganic \& Medicinal Chemistry 1999, 7:2139-2144.

26. Ostermeier M, Shim JH, Benkovic SJ: A combinatorial approach to hybrid enzymes independent of DNA homology. Nature Biotechnology 1999, I 7:1205-1209.

27. Dimarco AA, Romano AH: D-glucose transport system of Zymomonas mobilis. Applied and Environmental Microbiology 1985, 49:15I-157.

28. Stambuk BU, Franden MA, Singh A, Zhang M: D-xylose transport by Candida succiphila and Kluyveromyces marxianus. Applied Biochemistry and Biotechnology 2003, 105:255-263.

29. HMMTOP [http://www.enzim.hu/hmmtop/index.html]

30. Tusnady GE, Simon I: Principles governing amino acid composition of integral membrane proteins: application to topology prediction. Journal of Molecular Biology 1998, 283:489-506.

31. Tusnady GE, Simon I: The HMMTOP transmembrane topology prediction server. Bioinformatics 200I, I 7:849-850.

32. Saier MH: Vectorial metabolism and the evolution of transport systems. Journal of Bacteriology 2000, 182:5029-5035.

33. Qiu ZY, Nicoll DA, Philipson KD: Helix packing of functionally important regions of the cardiac $\mathrm{Na}^{+}-\mathrm{Ca}^{2+}$ exchanger. Journal of Biological Chemistry 200I, 276: 194-199.

34. Ren XY, Nicoll DA, Philipson KD: Helix packing of the cardiac $\mathrm{Na}^{+}-\mathrm{Ca}^{2+}$ exchanger - proximity of transmembrane segments I, 2, and 6. Journal of Biological Chemistry 2006, 28I:22808-228I4.

35. Ren XY, Nicoll DA, Galang G, Philipson KD: Intermolecular crosslinking of $\mathrm{Na}^{+}-\mathrm{Ca}^{2+}$ exchanger proteins: evidence for dimer formation. Biochemistry 2008, 47:608I-6087.

36. Joo H, Lin ZL, Arnold FH: Laboratory evolution of peroxidemediated cytochrome P450 hydroxylation. Nature 1999, 399:670-673.

37. Simmons CW, VanderGheynst JS: Transient co-expression of post-transcriptional gene silencing suppressors and beta-glucuronidase in harvested lettuce leaf tissue does not improve recombinant protein accumulation in planta. Biotechnology Letters 2007, 29:641-645.

38. Maniatis T, Fritsch E, Sambrook J: Molecular cloning: a laboratory manual Cold Spring Harbor, N.Y: Cold Spring Harbor Laboratory Press; 1989.
Publish with Bio Med Central and every scientist can read your work free of charge

"BioMed Central will be the most significant development for disseminating the results of biomedical research in our lifetime. "

Sir Paul Nurse, Cancer Research UK

Your research papers will be:

- available free of charge to the entire biomedical community

- peer reviewed and published immediately upon acceptance

- cited in PubMed and archived on PubMed Central

- yours - you keep the copyright
BioMedcentral 